\title{
The Swedish Fiscal Policy Framework and Intermediate Fiscal Policy Targets ${ }^{a}$
}

Torben M. Andersen ${ }^{\mathrm{b}}$

JEL-Classification: H6

Keywords: debt, debt brake, fiscal rules, Sweden

\section{Introduction}

The importance of fiscal policy planning and monitoring has been brought to the fore by the financial crisis. Underlying the so-called sovereign debt crisis are not only the effects of the crisis but more importantly failures to consolidate public finances in the past and to undertake reforms addressing future pressure on public finances arising from demographic changes and other forces. It is widely perceived that this situation has arisen due to political deficiencies causing deficit biases and myopia in fiscal policy planning.

This has prompted a reinforced interest in rules and institutions for fiscal policy. With a lag this discussion is similar to the earlier discussion in relation to monetary policy. For monetary policy there has been a significant shift towards independent and rule-based policy making ${ }^{1}$. Monetary policy targeting builds on an announced inflation target, implementation with focus on inflation forecasts (stabilizing expectations) and a high degree of accountability/transparency. The institutional framework is an independent central bank with a mandate for price stability, and which thus can be held accountable for its policy decisions relative to the mandate.

Although there has been proposals to develop similar independent institutions for fiscal policy (Wyplosz, 2005; CalmFors, 2003), the consensus is that

a This paper is based on a presentation at the conference "The Swiss Debt Brake - Ten Years On", Study Center Gerzensee. Comments and suggestions by the participants are gratefully acknowledged. The author served as deputy chairman of the Swedish Fiscal Policy Council in the period 2007-2011.

b Department of Economics and Business, CEPR, CESifo and IZA, Aarhus University.

1 There is a vast theoretical and empirical literature on monetary policy rules and targeting. See Svensson (2011) for a recent overview. 
this is not feasible without interfering too much in the policy decision process and the autonomy of democratically elected governments. Instead the focus has been on the development of fiscal policy targets and rules with the purpose of increasing the political costs of opportunism and shortism in economic policy making. These costs can be further increased by assigning independent institutions (watch dogs) a role in monitoring and commenting upon the extent to which actual policies have followed the fiscal targets and rules (Calmfors and WREN-LeWIS, 2011).

Sweden is a front-runner in defining intermediate targets for fiscal policy (fiscal rules) as well as in setting up an independent fiscal council to monitor and comment on developments. Swedish public finances are among the most sound in the OECD with a low debt level (reflecting consolidation over the years) and meeting the requirements for fiscal sustainability. Accordingly there has been an interest in understanding the Swedish case.

The Swedish fiscal policy framework has developed over the years ${ }^{2}$, but has its background in the need to consolidate public finances after a deep crisis in the early 1990s. In 1992 the public deficit was 11\% of GDP and public debt was growing (peaking at close to $90 \%$ of GDP), and this situation prompted a consolidation of public finances. Initially this was crisis management, but eventually this developed into the fiscal policy framework with well-defined intermediate targets for the management of public finances (since 1997), which was later strengthened by the establishment of a fiscal policy council in 2007.

This paper takes a closer look at the Swedish case as the stepping stone for a more general discussion of how to set intermediate targets for fiscal policy and the role fiscal councils may have in strengthening political accountability and thus ultimately credibility of fiscal policy. The Swedish case is of general interest not only because Sweden has been a front-runner but also because the fiscal policy framework has been fairly successful. The paper first gives a short introduction to the Swedish policy framework and the development in key fiscal policy variables in Section 2. This is followed by a discussion of accountability in fiscal policy and the role of intermediate target and independent fiscal policy councils in Section 3. While there has been much discussion on the role of policy rules and fiscal councils, there has been less discussion of the appropriate intermediate targets for fiscal policy. The general issues in relation hereto are discussed in Section 4, and the possible specific targets are discussed in Section 5. The paper also relates the Swedish policy framework to the recently enacted fiscal compact in EU in Section 6, and provides a few concluding remarks in Section 7.

2 See e.g. Calmfors (2012) and Flodén (2012). 


\section{The Swedish Fiscal Policy Framework}

The Swedish fiscal policy framework (Swedish Ministry of Finance, 2011a) has three core elements: i) An expenditure ceiling set in nominal terms. The ceiling is set for the current and the coming three years. A budget buffer is included to deal with unforeseen expenditures, given the ceiling resources are allocated across expenditure areas (there are 27 such areas) in a top-down process. ii) A surplus target requiring a budget surplus of $1 \%$ of GDP on average across the business cycle, which in turn is monitored by different indicators (see below), and iii) a balanced budget requirement for municipalities.

The development in the key fiscal policy variables relevant to the fiscal policy framework are given in Figure 1. The figure shows the development in the budget balance (primary and total balance) as well as the debt level (Gross debt and Maastricht debt). The figures clearly display the crisis in the 1990s as well as the subsequent consolidation.

The surplus target is monitored via three indicators ${ }^{3}$ : i) 10 year historical average computed for both the actual and the cyclically adjusted budget balance, ii) a seven year indicator (past three years, current year, and coming three years) also computed for the actual and the cyclically adjusted budget balance, and iii) the cyclically adjusted budget balance. Table 1 displays the recent assessment of the budget position including both the forward measure and the assessment indicators.

Table 1: Indicators for Public Sector Balance Relative to Target

\begin{tabular}{lccccc}
\hline & 2011 & 2012 & 2013 & 2014 & 2015 \\
\hline Budget balance & 0.1 & -0.3 & 0.3 & 1.6 & 3.0 \\
\hline 10 year average & 0.7 & & & & \\
$\quad$ - cyclically adjusted & 1.2 & & & & \\
7-year indicator & 0.4 & 0.5 & 1.2 & & \\
$\quad$ - cyclically adjusted & 1.6 & 1.8 & 2.0 & & 3.2 \\
\hline Cyclically adjusted balance & 0.7 & 1.2 & 1.6 & 2.1 & \\
\hline
\end{tabular}

Source: Ministry of Finance (2012).

3 The indicators have changed over time, see e.g. Swedish Fiscal Policy Council (2011). 
Figure 1: Public Sector Balance and Debt, 1990-2012.

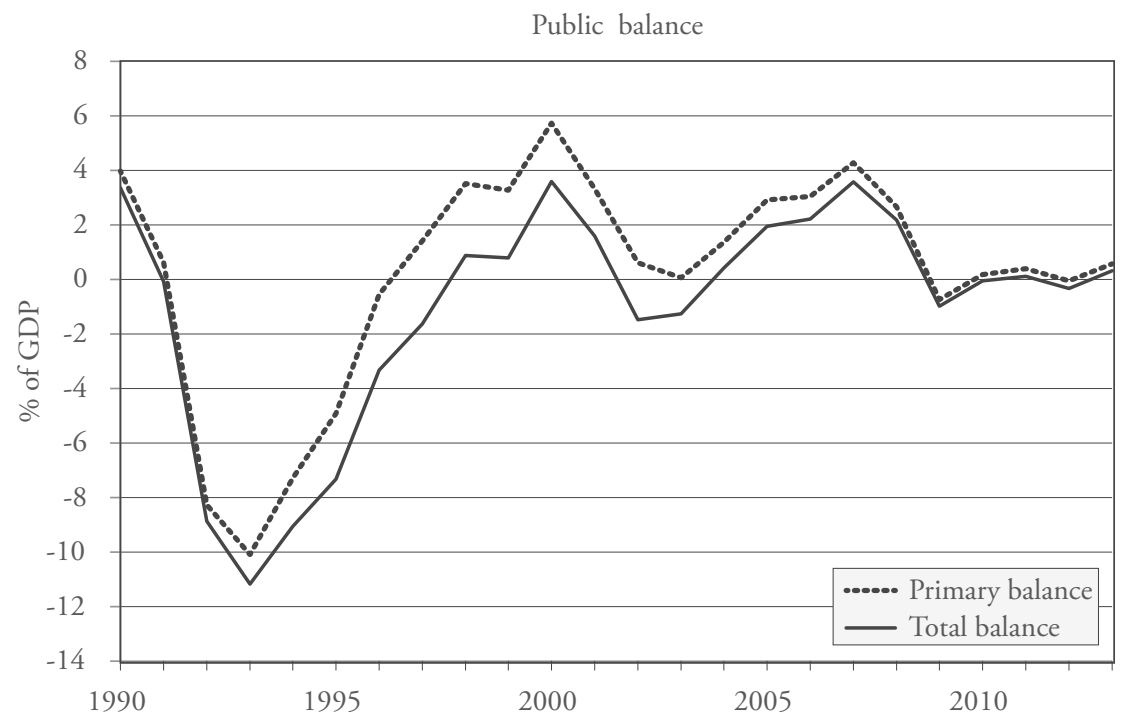

Public debt

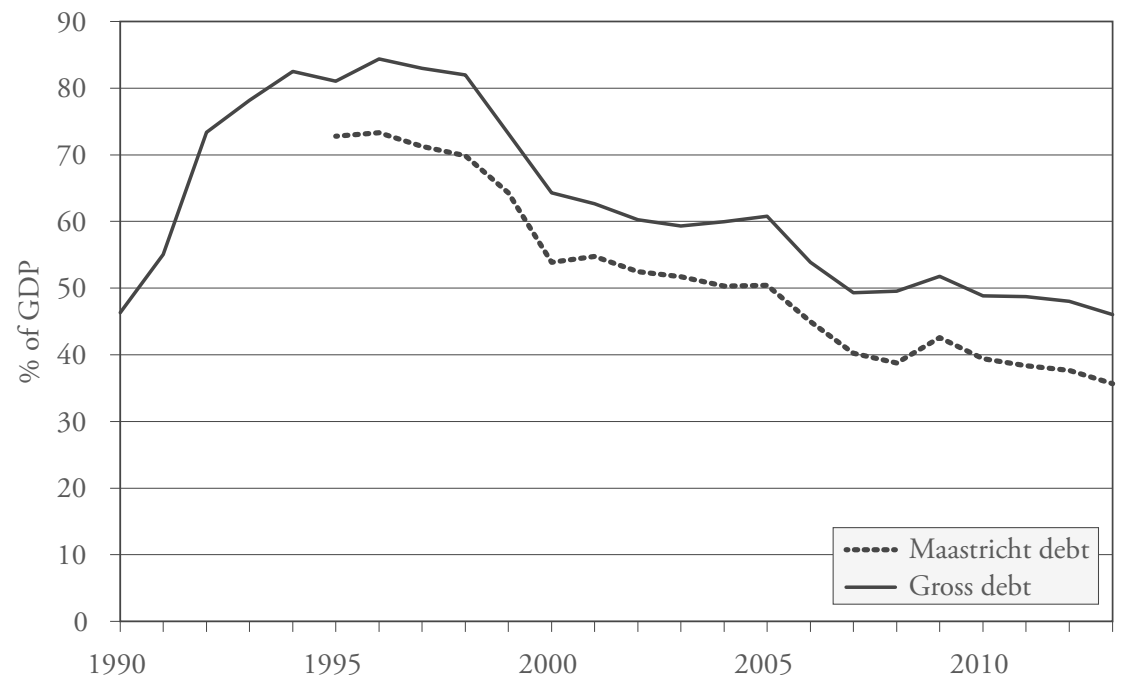

Source: www.ilibraryoecd.org 
The expenditure ceiling is a key element in a top-down procedure in expenditure planning which enforces a stronger prioritization between different expenditure areas since the overall target for total expenditures has to be fulfilled. The surplus target is set with an aim both to ensure some consolidation and to increase the ability to handle demographic changes, see e.g. Swedish Fiscal Policy Council (2008). As seen from Figure 2 the ceiling has been respected over time. The figure also shows that it has been a political aim to reduce the expenditure share.

Figure 2: Expenditure Ceiling and Actual Expenditures - Sweden 1997-2014.

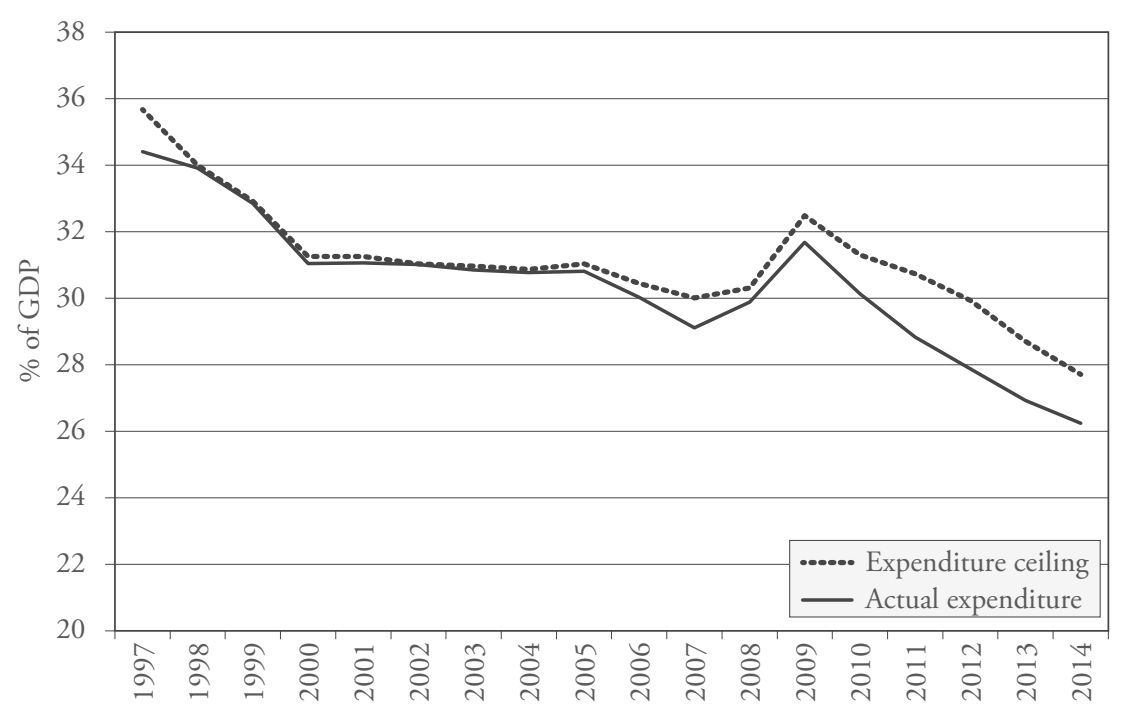

Note: Data for 2011-2014 are forecasts

Source: Swedish Ministry of Finance (2011a, 2012).

A fiscal policy council was established in 2007 to further strengthen the fiscal policy framework. The task of the council is to evaluate fiscal policy, stabilization policy, sustainability and fiscal policy targets, but also more widely growth and employment (structural policies). It is also part of the task to assess the transparency and motivation as well as analyse underlying fiscal bills, economic policy proposals etc. Finally, the council is also seen as a means to improve the basis for an informed public debate on economic policy. 
The council is independent with its own small secretariat. It has 6 (earlier 8) members. The main output is an annual report - Swedish Fiscal Policy - which includes detailed discussions and analyses of developments in economic policy in general and fiscal policy in particular. The core elements are an assessment of the extent to which the intermediate fiscal policy targets are met and a discussion of fiscal sustainability analyses. The report also explicitly comments on the substance and process underlying fiscal policy formation. In addition each report takes up specific issues, which vary from year to year, e.g. tax structure, labour market issues. The council does not make its own business cycle forecasts. The council does not in a pro-active way make explicit policy recommendations in a forward looking perspective, but via comments on both previous and planned policies it is effectively making policy recommendations.

The report is formally submitted to the government and forms the basis for discussions in parliaments about economic policy. The report has wide media attention. In addition the council (mainly via the chairman) is engaged in public debates on issues related to the tasks of the council.

\section{Fiscal Policy Targets and Councils}

The fundamental policy targets for the public sector include the size and structure of the public sector. It is a political question to settle these issues. The purpose of fiscal policy targets and councils is not to constrain these choices but to ensure that they are based on an explicit consideration of the costs and benefits. In particular as concerns the public budget, it is a key purpose to ensure that biases and myopia as well as time-inconsistency do not affect fiscal policy. The key issue is to avoid deficit biases, unsustainable debt accumulation (risky position) as well as unintentional intergenerational burden shifting.

The main role of rules and councils is to strengthen political accountability; that is, to ensure that policy decisions are in accordance with stated objectives and intentions. A broad definition of accountability has that

Accountability ensures that actions and decisions taken by public officials are subject to oversight so as to guarantee that government initiatives meet their stated objectives and respond to the needs of the community they are meant to benefit, thereby contributing to better governance (WORLD BANK, 2006).

And in a more narrow definition

A relation between an actor and a forum, in which the actor has an obligation to explain and to justify his or her conduct, the forum can pose questions and pass judgement, and the actor may face consequences (Bovens, 2006). 
Clear and well-defined rules can serve to strengthen accountability. Rules are defined in terms of intermediate targets which should be well defined, easy to monitor and under reasonable control by the policy maker. If so, deviant or opportunistic behaviour is revealed, and policy control mechanisms can be enforced.

There are two overriding requirements of importance in setting intermediate targets for fiscal policy. First, automatic stabilizers should be allowed space to operate. This is the rule-based part of fiscal policy and it is widely accepted to be stabilizing. Secondly, the fiscal targets should not preclude political prioritization, but they should ensure that systematic imbalances do not arise between revenues and expenditures for the public sector. In short they should contain deficit biases and ensure that the intertemporal budget constraint is respected, but they must also leave room for political prioritization on the size and structure of the public sector.

Few intermediate targets for fiscal policy satisfy the abovementioned requirements. It is riddled with difficulties to set simple and unambiguous targets which are directly related to variables under political control. Intermediate targets are important for planning etc. However, intermediate targets are guideposts for policy, but they do not put policy on an autopilot. Problems of inferring both as regards the business cycle position and the underlying economic structure raise vast problems of information and interpretation, and this makes it clear that all these contingencies related to possible states of nature cannot be captured in a simple rule.

Simple rules have the advantage that they are easy to communicate, but they leave problems of interpretation. The problems of information and interpretation of complex issues in fiscal policy make it difficult for the general public to interpret whether developments are in accordance with stipulated policy objectives. In this nexus experts play a role, and an independent fiscal council may perform the role of the auditor on the part of the general public. Publicity via a council sharpens politicians and protects civil servants from political pressures, and it serves to inform the general public debate. It allows for outside control on a continuous and independent basis.

In short intermediate targets and fiscal policy councils are to some extent substitutes in ensuring accountability in economic policy, but they reinforce each other in an important way. Intermediate targets allow the council to be more explicit in its monitoring, and a council makes it clearer that the intermediate targets have to be followed. Economic policy is not an engineering control problem, and therefore there is both an important ex ante and ex post role in relation to assessment of economic policy. The ex ante role refers to the formulation of 
consistent economic plans, and the ex post role to the issue of whether intended policy plans are followed. While intermediate targets have an important role in both dimensions, an independent council can better make the necessary assessments, not least the ex post control.

\section{Setting Intermediate Fiscal Policy Targets}

For all indicators or targets there is both a filtering problem and an error-correction problem. The filtering problem refers to the need to separate cyclical and temporary influences beyond political control from political decisions. The purpose of targets is to hold politicians accountable for their policies relative to their stated targets/objectives. The error-correction problem is concerned with how to adjust to failures and shocks in the past so as to remain on track relative to the medium to long run objectives. An immediate response to bringing the variable to its target value will not in general be optimal since it, for a number of reasons, may be desirable to smoothen policy responses. Hence, there is a response problem. This problem is larger, the larger the filtering problem since there is a risk of overreacting to temporary variations which have been incompletely separated from trends ${ }^{4}$ (ANDERSEN, 2012). Ideal targets minimize the filtering problem and specify an error-correction mechanism.

Two different approaches may be taken in setting intermediary targets, either a fixed time $e^{5}$ or a target zone approach. Targets are set for a given period (e.g. expenditures or debt should be below a certain level by the end of the planning period) at the end of which policies/targets are revised and set for a new period. ${ }^{6}$ This has the advantage that it is easy to communicate and matches political desires to formulate plans, e.g. after an election. One problem is that clear needs

4 The 7 year indicator, cf. Table 1, both filters the past (minimizing risk of reacting to temporary changes) and smoothens responses (not taking all the adjustment immediately).

5 In e.g. Denmark a tradition of making economic plans with a 10 year horizon setting target for the period has developed.

6 The setting of a target value may be particularly difficult when there is an underlying trend due to e.g. demographic changes. Setting the target at the average value planned over the period would lead to systematic differences over the entire planning period. This is an argument for a short planning period, but a too short period leaves little flexibility. For the target zone a similar problem is that the targeted value is time dependent, and therefore the target zone is a moving zone. This is very difficult to handle in terms of communication and thus transparency, and if the pragmatic solution is to shift the target values at discrete intervals, then this effectively becomes a fixed time horizon plan. 
for revision of targets may arise before the end of the planning period ${ }^{7}$. This suggests that a new plan should be launched in such cases. But this possibility also opens for a more lax interpretation of the whole framework, "we missed the target, let us formulate a new target for a new period"; i.e. there is a risk that the commitment value of the framework is reduced. An alternative is to set a target zone with target values and allowing variations within some interval, and to undertake policy adjustments if the boundaries of the target zone are hit (such target zones are known from exchange rate policies and pricing policies). ${ }^{8}$ This may seem a more flexible solution since it allows room for some variations, only calling for initiatives when the boundaries of the zone are not violated. An obvious question is how to set the threshold for the zone (how wide should it be?). Such a scheme also opens for a possible bias by leaning to one side of the band (for instance the upper limit for expenditures or debt), creating asymmetries and thereby increasing the exposure to shocks.

A key question is whether there should be only one or several intermediary targets. The underlying uncertainty and the problem of unravelling the underlying state of the economy are arguments for having a portfolio of intermediary measures since they all have pros and cons. The primary advantage is that many targets imply some reduction of uncertainty by "averaging" and allow some learning. A disadvantage is that it leaves open when to react (when one or all measures are off target?), but also that it creates lack of transparency since policy makers may shift between targets depending on performance; i.e. it is more difficult to hold policy makers accountable with several targets. Overall this goes in the direction of having few intermediate targets.

7 The determination of the planning period involves a trade-off between flexibility (short period) and commitment (long period). There is a risk of front loading within the planning period, e.g. reaching the expenditure or debt target early in the period, and the question is how discipline is enforced in this case.

8 Target zones for fiscal policy are known from the public finance requirements of the Stability and Growth Pact having one-sided targets in terms of a maximum debt-to-gdp ratio (60\%) and budget deficit relative to gdp (3\%). The fiscal compact for EU countries also has a onesided zone defined in terms of the structural budget balance relative to gdp (0.5\%). Prior to the financial crisis the UK had a one-sided debt target stipulating a maximum of $40 \%$ of gdp. 


\section{Intermediate Targets for Fiscal Policy}

In the formulation of economic policy plans it is natural to take outset in medium/long-run objectives. The overriding requirement is to ensure fiscal sustainability. In particular demographic changes make this both important and difficult. At the same time it is important that there is room to accommodate business cycle fluctuations both via the automatic stabilizers and eventual discretionary policies.

Approaching demographic changes have made assessment of fiscal sustainability an integral part of policy planning (see e.g. the sustainability reports from the European Commission, the latest version being European Commission (2012)). One problem in translating the requirement of fiscal sustainability into explicit targets is that fiscal sustainability does not define a unique path for public finances (including the debt level). Various paths can be consistent with fiscal sustainability. A common measure (S2) is to compute the permanent change in the primary budget balance (in \% of GDP), which ensures that the intertemporal budget constraint for the public sector is exactly met.

Since the aim is to ensure fiscal sustainability, it may seem obvious to make the sustainability indicator the target (proposed by RiKSREvisionen, 2009). . However, this indicator is a calculated metric which is not continuously measured, and it may be difficult to monitor (cannot be easily computed by outsiders). Moreover it is informationally demanding to compute and sensitive to assumptions, for a discussion see e.g. Andersen (2010). Although this is a useful metric in identifying sustainability problems it has no normative implications, and hence it does not easily translate into an intermediate target for fiscal policy.

A pragmatic approach may be to make the debt level the target since it is regularly measured and (reasonably) well understood. It may be argued that the public debt level is the key variable affecting future generations. Future generations may want to take different decisions than current generations, and it is not obvious that the former should constrain this possibility. Bygones are bygones, and therefore the relevant part of the past of importance for future decision making is the debt level; i.e. "leaving all future generations with the same options as current generations". This is also illustrated by the fact that any assessment of fiscal

9 In Swedish Ministry of Finance (2010) it is proposed to divide sustainability into three groups depending on the sustainability indicator S2. If the absolute value of the indicator is less than one, this is taken to imply that the current policies are sustainable, and there are thus no financial reasons for policy changes. A sustainability indicator between 1 and 3 indicates that the economic policy most likely needs to be changed, while an absolute value above 3 indicates that there is a clear case for undertaking a policy change. 
sustainability is based on the initial debt level in combination with projected paths for revenues and expenditures. Making the debt level an intermediate target does however raise some problems. First, the theoretical appropriate debt concept should be the net debt and not the gross debt. But the former is associated with significant measurement problems. Second, the debt level may in the short run display variations due to asset price variations which may be unrelated to policy decisions. If these variations are perceived as temporary, they should not affect assessments of fiscal sustainability significantly. Finally, changes in the debt level in the short run arise due to business cycle fluctuations and they need to be sorted out. This however runs via the budget balance, and thus the question of separating the cyclical influences on the budget from the more systematic applies. This naturally points to some measure of the budget balance as a more obvious intermediate target.

It is well known that the budget position is very sensitive to the business cycle situation. These variations have to be separated from changes due to policy decisions, and it is important to allow for the automatic stabilizers to work. Hence, defining a narrow intermediate target based on the actual budget position is highly problematic. The obvious alternative is to make the structural budget position the intermediate target. ${ }^{10}$ The basic idea is to consider the underlying budget position in a normal business cycle situation. While this is theoretically an appealing concept which it is straightforward to define in a theoretical setting, it is very difficult to operationalize. The structural budget position cannot be directly measured and it is assessed via the cyclically adjusted budget (CAB) position that is, removing the cyclical component from the actual budget position.

The standard procedure for finding the $\mathrm{CAB}$ is to correct the actual balance for business cycle influences and one-off items, i.e.

$$
\text { structural balance }=\text { actual balance }- \text { cyclical component }- \text { one-off items }
$$

10 The cyclically adjusted budget balance (CAB) has attained increasing importance in fiscal policy making and monitoring. This is most clear in the case of the EU. While the Stability and Growth Pact (SGP) initially was formulated in terms of nominal public finance indicators (deficits and debts relative to GDP), it soon became clear that this was problematic due to the cyclical sensitivity of these measures. With the revision of the SGP in 2005, the role of the $\mathrm{CAB}$ was elevated through the emphasis on ensuring budget positions that are "close to balance or in surplus over the business cycle". With the recently agreed fiscal compact for the $\mathrm{EU}$, the $\mathrm{CAB}$ has become an explicit target in the form of the "lower limit of a structural deficit of $0.5 \%$ of the gross domestic product at market prices", cf. below. 
There are various methods by which to assess the cyclical component ${ }^{11}$ differing in the degree of sophistication in terms of methods and disaggregation (Aasdalen et al., 2011; Larch and Turrini, 2009; Girouard and André, 2005). The usual procedure is to capture the business cycle situation by e.g. the output gap and combine it with the sensitivity of taxes and expenditures to compute the cyclical component. Adjustment for one-off items ${ }^{12}$ is usually done on a more discretionary basis. The precise method used to assess the structural budget varies a lot across countries.

The method used in assessing the structural budget balance may thus be characterized as a residual based method since the structural balance is measured by the $\mathrm{CAB}$ found as the residual remaining in the actual budget after controlling for the cycle position and the one-off items. While this conceptually makes sense since it aims to remove factors which are considered to be temporary, it suffers from the problem that all measurement problems, errors and noise end up in the measure of the $\mathrm{CAB}$, which is then used as the measure of the structural budget position. This is problematic both when changes in the structural budget balance are used as a measure of discretionary policy changes, and when they are used to assess the sustainability of public finances.

These problems can be illustrated in various ways. It is to be expected that a structural measure displays less variability than the actual measure since the idea is to remove the cyclical component. However, actual measures of the cyclically adjusted budget balance tend to display at least the same degree of variability as the actual budget balance, see ANDERSEN (2012). This suggests that substantial noise remains in the cyclical measure exactly due to its residual character. It is well known that estimates of the structural budget balance are subject to substantial revisions between early ex ante and later ex post evaluations. ${ }^{13}$ It is also

11 Note that the CAB is not directly estimated, although some coefficients are estimated, as may be the potential output etc.

12 The code of conduct for the Stability and Growth Pact states "one-off measures having a transitory effect that does not lead to a sustained change in the intertemporal budget position", see "Specifications on the implementation of the Stability and Growth Pact and guidelines on the format and concept of stability and convergence programmes", endorsed by the ECONFIN Council on 11 October 2005.

13 Also changes far in excess of what can be attributed to policy changes. The problem of assessing the structural budget balance relates to estimates of cyclical budget sensitivities, and output gaps as well as temporal and one-off items affect the budget. Moreover the method applied is a residual method in the sense that the structural measure is found by subtracting cyclical and temporary effects from the actual balance. All errors in this procedure are thus attributed to the structural balance. For a discussion see e.g. Swedish Fiscal Policy Council (2011). 
well established that measures of the $\mathrm{CAB}$ produced prior to the financial crisis overestimated the structural position by taking temporary revenue increases to be permanent, see e.g. JoumARD and ANDRÉ (2008). The "biased" fiscal policy in the period can thus not solely be attributed to political biases, also the information and advice provided to policy makers on the structural budget position were deficient.

Defining an intermediate fiscal target on the basis of a measure of the structural budget balance thus raises several issues. It is important to improve the methods to reduce the noise component and to make the procedure in computing the structural budget balance transparent. Moreover it is important to be explicit about the uncertainty in the measure of the structural budget balance which implies that a narrow intermediate target defined for the structural budget balance (see below on the fiscal compact) is problematic. Finally, the error correction mechanism both for updating measures of the structural budget balance in the past and in relation to deviations from targets becomes important. Such deviations accumulated in the debt level and ex post deviations may thus lead to substantial long-run problems if the framework is not explicit on how to address such deviations. Note that the Swedish system via the various indicators (see e.g. Table 1) addresses these problems.

Finally, there is the question whether intermediate targets for the budget position (or eventually the debt level) have to be supplemented by an expenditure target. A budget target obviously involves both the expenditure and the revenue side. An explicit expenditure target may have several advantages. Given the uncertainty in assessing the structural budget position (and a pro-cyclical bias) there is a risk that targets defined only in terms of the budget position lead to a pro-cyclical bias in fiscal policy. ${ }^{14}$ This can be contained by expenditure targets. Moreover, explicit expenditure targets serve the role of ensuring a more explicit prioritization process in the determination of public expenditures both with respect to the level and the composition.

14 Holm-Hadulla et al. (2010) show that expenditure restraints and numerical expenditure rules are important for maintaining budgetary discipline. 


\section{The Swedish Fiscal Policy Framework and the New European Fiscal Compact}

It is interesting to compare the Swedish fiscal framework with the fiscal rules associated with the Stability and Growth Pact for European Union countries. The latter has undergone some changes over time but has recently been amended by the so-called fiscal compact. The fiscal compact is inspired by the German fiscal framework.

Germany has recently (2009) introduced a fiscal framework with the following key elements: i) The structural budget balance is to exceed $-0.35 \%$ of $\mathrm{GDP}^{15}$, ii) this limit can be exceeded in case of large natural disasters (escape clause), iii) deviations from the target are accumulated (control fund) and an adjustment has to be undertaken if the accumulated deviations exceed 1.5\% of GDP, iv) all "Länder" are subject to a balanced budget requirement.

The German system has inspired the so-called European Compact (European Council, 2011). This strengthens the Stability and Growth Pact by requiring, among other things, i) that central government budgets shall be balanced or in surplus. This principle shall be deemed respected if, as a rule, the annual structural deficit does not exceed $0.5 \%$ of nominal GDP. However, for countries where the debt level is below $60 \%$, a deficit of up to $1 \%$ of GDP is allowed. ii) Such a rule will also be introduced in member states' national legal systems at constitutional or equivalent level. The rule will contain an automatic correction mechanism that shall be triggered in the event of deviation. It will be defined by each member state on the basis of principles proposed by the Commission. This also contains common principles for the role and independence of institutions (i.e. a Fiscal Advisory Council) responsible at national level for monitoring the observance of the rules to ensure that the "automatic correction mechanism" will actually work. In addition initiatives are proposed to strengthen the monitoring and corrective arm.

Many details of the new European Fiscal Compact are yet to be determined. There are, however, some problematic parts. Setting an intermediary target as a one-sided target zone for the structural budget balance is problematic for several reasons.

The determination of structural budget balances is riddled with problems, and methods differ across countries. ${ }^{16}$ Assessments of structural budget balances are

15 Note that the overall deficit level for the public sector is $-0.5 \%$, but since about $70 \%$ of debt is at the federal level, the federal deficit limit has been set at $-0.35 \%$, see BAUMAnN et al. (2008).

16 OECD uses a rather aggregate approach, while ECB uses a more disaggregate approach. Note also that the method used by the European Commission has been frequently changed. 
not easily made and reproduced, and this makes problems of control and comparison difficult. A narrow target for the structural budget balance risks inducing excessive policy activism contrary to the intentions underlying the Growth and Stability Pact. The reason is that a country will have to adjust its fiscal policy to any change in the structural balance to avoid a conflict with the target, but this implies reaction to noise in the measure of the structural budget balance, see Andersen (2012). Since this noise is not trivial, the target creates an "activism" bias in fiscal policy.

The one side zone is also problematic since it is unconditional of other parts of public finances. One concern is that the lower bound is in conflict with stabilization policy. Automatic budget responses and thus the automatic stabilizers will not affect the structural budget balance, and can thus be contained within the 3\% limit on the actual budget. However, a sufficient margin for countries with large automatic stabilizers requires that the structural balance is in surplus (as has been argued in e.g. Sweden). However, maintaining systematic surpluses to attain stabilization freedom is problematic, and although many countries are in a situation where consolidation is needed at the moment, this is a potential source of conflicts, especially since not all European countries face large sustainability problems.

A target for the structural budget balance has implications for the long-run debt level. In the long run the debt-to-gdp ratio is determined by the budget-togdp ratio and the nominal growth rate of GDP. ${ }^{17} \mathrm{~A}$ budget position above minus $0.5 \%$ of GDP (or $1 \%$ of GDP) will thus in the medium to long run induce a rather low debt level. It is not clear that such a low debt level is optimal, and it is not something that gets ready support from theoretical considerations. It also points out that imposing such a strict budget target as a common requirement independent of the underlying public finance stance is problematic. For countries with relatively low debt and fiscal sustainability, this is particularly problematic.

Finally, the fiscal compact lacks the level dimension. While it may be argued that the common interest is related to deficits and debts, it remains that levels targeting is important to achieve these targets, and as the Swedish experience shows the expenditure target has been crucial in reaching the targets related to budget balance and consolidation.

17 The long-run value of the debt-to-gdp ratio $d$ is given as $d=((1+g) / g) b$, where $b$ is the budgetto-gdp ratio and $g$ is the nominal growth rate for gdp. For a budget ratio b equal to $3 \%$ the debt ratio will be $60 \%$ if the underlying nominal growth rate is $5 \%$ (the original Stability and Growth Pact numerology). With a nominal growth rate of $5 \%$ and a budget ratio of $0.5 \%$, the debt level becomes approximately $10 \%$. With a growth rate of $4 \%$ it becomes $13 \%$, and for $3 \%$ nominal growth $17 \%$. For a deficit limit at $1 \%$ of GDP the debt levels will be the double of the abovementioned numbers. 


\section{Conclusion}

It is a well known problem to establish causality between fiscal rules and institutions on the one hand and fiscal outcomes on the other. Favourable fiscal outcomes may ultimately depend on political willingness and capital to pursue credible policies, and such policy makers may also set explicit fiscal targets and appoint independent fiscal institutions. However, both rules and fiscal councils serve the purpose of increasing the political costs of deviating behaviour whether driven by myopia, time consistency or political opportunism.

Sweden is a front-runner in the setting of fiscal targets and appointment of an independent fiscal council. The background is a crisis in the 1990s and a need to consolidate public finances, not unlike the situation for many European countries today. The Swedish case is therefore interesting, also because the system has been maintained after the acute crisis management was ended. The framework has thus been instrumental in ensuring that Sweden during the financial crisis has been able not only to let automatic stabilizers work (and they are strong given the extended welfare state) but also to pursue an expansionary fiscal policy. At the same time requirements for fiscal sustainability are met.

While the Swedish fiscal framework has clearly defined targets it also allows for flexibility in the monitoring of the evolution in the public budget via various indicators. This implies that account is taken of risk and measurement problems, but it also includes an error-correction element to keep fiscal policy on track. The Swedish system has a proven track record and a number of properties which are more attractive than the rigid system imposed via the fiscal compact for EU countries. The latter is narrowly defined in terms of the structural balance which is only measured with large uncertainty, and therefore this scheme risks inducing excessive policy activism since policy makers respond to noisy measures of the structural budget balance. Moreover in a medium term perspective it implies a very strong consolidation of public finances which may not be optimal and which does not take account of country differences.

\section{References}

Aasdalen, Helga B., Yngwar Dyvi, Anders Harilstad, Per M. Konsrud and Pal Stetten (2011), «Finansdepartementets beregning af strukturell, oljekorrigert budsjettbalanse», Finansdepartementet, Arbeidsnotat, Oslo.

Andersen, Torben M. (2010), "Fiscal Sustainability in the Wake of the Financial Crisis", Nordic Economic Policy Review 1, pp.71-109. 
Andersen, Torben M. (2012), "Fiscal Policy Targeting under Imperfect Information", Journal International Money and Finance forthcoming.

Baumann, Elke, Elmar Dönnebrink, and Christian Kastrop (2008), "A Concept for a New Budget Rule for Germany", CESifo Forum 2/2008, pp. 37-45.

Bovens, Mark (2006), "Analysing and Assessing Public Accountability - A Conceptual Framework", EUROGOV Working Paper C-06-01.

Calmfors, Lars (2003), "Fiscal Policy to Stabilize the Domestic Economy in the EMU”, CESifo Economic Studies, 9, pp. 19-53.

Calmfors, Lars (2012), "Sweden: Watchdog with a Broad Remit", CESifo Working Paper No. 3725.

Calmfors, Lars, and Simon Wren-Lewis (2011), "What Should Fiscal Councils Do?", Economic Policy, 26, pp. 649-695.

European Commission (2012), Sustainability Report 2009, Bruxelles: European Commission 2012

ECOFin Council (2005), Specifications on the Implementation of the Stability and Growth Pact and Guidelines on the Format and Concept of Stability and Convergence Programmes, Brussels.

European Council (2011), Treaty on Stability, Coordination and Governance in the Economic and Monetary Union, Brussels.

Flodén, Martin (2012), "A Role Model for the Conduct of Fiscal Policy? Experiences from Sweden”, CEPR Discussion Paper No. 9095.

Girouard, Nathalie. and Christophe André (2005), "Measuring Cyclicallyadjusted Budget Balances for OECD Countries", OECD Economics Department Workings Paper No. 434.

Holm-Hadulla, Fédéric, Sebastian Hauptmeier, and Philipp Rother (2010), "The Impact of Numerical Expenditure Rules and Budgetary Discipline over the Cycle", ECB Working Paper No. 1169.

Joumard, Isabelle, and Christophe André (2008), "Revenue Buoyancy and its Fiscal Policy Implications", OECD Working Papers No. 598.

Larch, Martin, and Alessandro Turrini (2009), "The Cyclically-Adjusted Budget Balance in EU Fiscal Policy Making: A Love at First Sight Turned into a Mature Relationship", Economic Papers, 374.

RiKSREVISIONEN (2009), "Tillämpningen av det finanspolitiska ramverket", Rapport 17, Stockholm.

Svensson, Lars E. O. (2011), "Inflation Targeting", in Handbook of Monetary Economics, Benjamin M. Friedman and Michael Woodford, eds., Vol.3b, chap. 22, Amsterdam: North-Holland. 
Swedish Fiscal Policy Council, various years, Swedish Fiscal Policy, Stockholm.

Swedish Ministry of Finance (2010), "Utvidgad redovisning av bedömningen av finanspolitikens hållbarhet", Promemoria.

Swedish Ministry of Finance (2011a), "Ramverket för finanspolitiken, Regeringens skrivelse", 2010/11:79.

Swedish Ministry of Finance (2011b), "Vårpropositionen", Stockholm.

Swedish Ministry of Finance (2012), "Vårpropositionen”, Stockholm.

World BANK (2006), "Accountability in Governance", Note

Wyplosz, Charles (2005), "Fiscal Policy: Institutions versus Rules", National Institute Economic Review, 191, pp.70-84.

\section{SUMMARY}

Sweden is a front-runner in defining intermediate targets for fiscal policy (fiscal rules) as well as in setting up an independent fiscal council to monitor and comment on developments. Swedish public finances are among the most sound in the OECD having been able to consolidate public finances and ensure fiscal sustainability, and they have maintained room for fiscal manoeuvre also during the financial crisis. This paper takes a closer look at the Swedish case as the stepping stone for a more general discussion of how to set intermediate targets for fiscal policy and the role fiscal councils may have in strengthening political accountability and thus ultimately credibility of fiscal policy. The Swedish fiscal framework is compared to the fiscal compact for EU countries, and it is argued that it has a number of desirable features. 